УДК 338.48

$10.17213 / 2075-2067-2019-4-117-122$

\title{
ВОЗМОЖНОСТИ ПАКЕТИРОВАНИЯ УСЛУГ ГОСТИНИЦЫ КАК ФАКТОР КОНКУРЕНТОСПОСОБНОСТИ СРЕДСТВ РАЗМЕЩЕНИЯ
}

\author{
(C) 2019 г. О. С. Мысова, О. В. Елисеева, Н. Г. Нагай
}

\section{Институт сферы обслуживания и предпринимательства (филиал) ДГТУ, г. Шахты}

Целью данного исследования является изучение опьта формирования пакетов выходного дня и применение его в деятельности гостинищы «Кава ди Пьетро». Результаты: на основе рассмотренного опыта формирования пакета выходного дня даны рекомендачии по формированию аналогичного пакета в гостинице «Кава ди Пьетро» с учетом имеющейся материально-технической базы.

Ключевые слова: гостиничные услуги; пакетирование услуг; лояльность гостей; пакет выходного дня.

The purpose of this study is to study the experience of forming weekend packages and its application in the activities of the "Cava di Pietro» Hotel. Results: on the basis of the reviewed experience of forming a weekend package, recommendations are made for forming a similar package at the "Cava di Pietro» Hotel taking into account the available material and technical base.

Key words: hotel services; service packaging; guest loyalty; weekend package.

Тенденцию пакетирования услуг сегодня активно поддерживают представители различных сфер предпринимательства, а гостиничный бизнес, безусловно, является одним из видов отраслей, в которых возможно и прибыльно применение продаж услуг, которые состоят из нескольких компонентов, объединенных в единое целое. Связывание различных видов услуг дарит отелю возможность повышать конкурентоспособность, привлекать новые сегменты потребителей, а также стимулировать возвращение постоянных гостей [1]. Данные обстоятельства придают изучению технологий пакетирования особую актуальность.

Пакет услуг представляет собой комплекс разнообразных предложений, объединенных одной ценой [2], и, следовательно, является комплексным продуктом, связывающим ряд услуг.

Создание комплексных продуктов путем комбинации уже известных простейших дает средству размещения возможность большего охвата рынка. При этом чем разнообразнее предложение, тем выше его ценность.

Структура предложений на рынке гостиничных пакетов выходного дня достаточно неоднородна. Многие отели предлагают очень скудный ассортимент услуг в пакетах этого типа, а отличие их от обычного размещения состоит только в цене. Такой подход к формированию пакета можно назвать очень поверхностным, так как он не рассчитан на привлечение какого-либо конкретного сегмента гостей, не обладает характеристиками уникального предложения и может привлечь гостя только своей ценой. Вариацией этого подхода является создание продуктов, отличающихся только поздним выездом или ранним заездом и не содержащих никакой индивидуализации услуг.

Пакеты выходного дня представляют собой частный случай «пакетов потакания» или «терпимости». Сложно выделить один сег- 
мент гостей, на который они были бы ориентированы. Такими продуктами могут пользоваться гости, которым необходимо в первую очередь краткосрочное размещение.

Эти пакеты особенно полезны бизнесгостиницам, так как позволяют повысить продажи номеров в субботу и воскресенье, когда отсутствуют деловые гости. Предложения являются ограниченными и, как правило, не действуют в праздничные и предпраздничные дни.

Рассмотрим опыт формирования пакета выходного дня на примере гостиницы «Кава ди Пьетро». Гостиница «Кава ди Пьетра» имеет категорию 3 звезды и существует с 2004 года. Основным сегментом гостей ООО «Кава ди Пьетро» сегодня являются деловые люди, прибывающие для переговоров, участия в конференциях и иных мероприятиях. Гостиница аттестована Российской Acсоциацией бизнес-туризма и предоставляет целый спектр дополнительных услуг в этой сфере [3]. Помимо деловых гостей, средство размещения обслуживает также туристов и семьи.

В рамках исследования был проведен анализ гостиничных продуктов гостиницы. Основным продуктом гостиницы являются услуги размещения. В стоимость каждого номера включается также услуга питания завтрак.

В качестве дополнительных предлагаются также услуги, представленные в таблице 1. Гостиница предлагает своим гостям сразу несколько специальных предложений (таблица 2).

\section{Дополнительные услуги гостиницы ${ }^{1}$}

Таблица 1

\begin{tabular}{|l|l|}
\hline \multicolumn{1}{|c|}{ Виды услуг } & \multicolumn{1}{c|}{ Информация об услуге } \\
\hline $\begin{array}{l}\text { Заказ билетов на } \\
\text { различные виды } \\
\text { транспорта }\end{array}$ & Стоимость услуги -9\% от стоимости билета. \\
\hline Автостоянка & Охраняемая автостоянка на территории гостиницы. \\
\hline Багаж & $\begin{array}{l}\text { Хранить багаж можно в камере хранения, расположенной на первом } \\
\text { этаже гостиницы. }\end{array}$ \\
\hline Сейф & Для хранения ценных вещей гости могут воспользоваться сейфами. \\
\hline Банкомат & Банкомат расположен при входе в гостиницу. \\
\hline $\begin{array}{l}\text { Оплата кредитными } \\
\text { картами }\end{array}$ & $\begin{array}{l}\text { К оплате принимаются кредитные карты: Сберкарт, Visa, VisaЕlectron, } \\
\text { МаstегСагд, Маеstrо, Сіrгыs. }\end{array}$ \\
\hline $\begin{array}{l}\text { Прачечная, глажение } \\
\text { и химчистка }\end{array}$ & $\begin{array}{l}\text { В каждом номере имеются специальные пакеты для прачечной и хим- } \\
\text { чистки и бланк заказа с прейскурантом. }\end{array}$ \\
\hline $\begin{array}{l}\text { Персональный } \\
\text { помощник }\end{array}$ & $\begin{array}{l}\text { Персональный помощник встречает гостя, планирует пребывание в } \\
\text { городе с учетом его пожеланий, сопровождает в качестве переводчика } \\
\text { и делает перевод необходимых документов, помогает организовать } \\
\text { встречу, переговоры, заказывает билеты в кино, театр, на выставку, } \\
\text { разрабатывает экскурсионную программу, бронирует билеты, номер } \\
\text { в гостинице. }\end{array}$ \\
\hline $\begin{array}{l}\text { Аренда комнаты } \\
\text { переговоров }\end{array}$ & $\begin{array}{l}\text { Для проведения деловых встреч к услугам гостей комната перегово- } \\
\text { ров, рассчитанная на 6-8 мест, включающая в себя все необходимое } \\
\text { оборудование для современных деловых людей. }\end{array}$ \\
\hline $\begin{array}{l}\text { Работа на персональ- } \\
\text { ном компьютере }\end{array}$ & $\begin{array}{l}\text { Гостям предоставляется возможность воспользоваться Пк в комнате } \\
\text { переговоров. }\end{array}$ \\
\hline
\end{tabular}

1 Составлено автором. 
Пакетов других типов гостиницей не сформировано, а существующие продвигаются очень слабо. Информация о них содержится только в специальном разделе на сайте гостиницы и является довольно скудной.

ООО «Кава ди Пьетро» располагает достаточными возможностями для создания новых пакетов:

- имеются номера различных категорий;

- собственное предприятие питания;

- широкий ассортимент разноплановых дополнительных услуг;

- выгодное расположение гостиницы.

Формирование пакетных предложений имеет для гостиницы «Кава ди Пьетра» осо- бую актуальность, так как любая гостиница, специализирующаяся на обслуживании бизнес-туристов, испытывает трудности с загрузкой в выходные и праздничные дни. Решением этой проблемы может стать внедрение пакета выходного дня.

Возможности применения услуг гостиницы в пакете выходного дня представлены в таблице 3.

Недостатком является отсутствие у гостиницы собственного бассейна, спортивного комплекса, анимационной службы, детской комнаты или штатной няни. Это означает, что для организации досуга гостей необходимо будет привлечь сторонних исполнителей.

\section{Специальные предложения гостиницы «Кава ди Пьетра»²}

Таблица 2

\begin{tabular}{|l|l|}
\hline \multicolumn{1}{|c|}{ Предложение } & \multicolumn{1}{|c|}{ Описание } \\
\hline Выходные дни и праздники & Скидка $10 \%$ на все услуги для обладателей дисконтных карт. \\
\hline $\begin{array}{l}\text { Для корпоративных } \\
\text { клиентов }\end{array}$ & $\begin{array}{l}\text { Система скидок: } 10 \% \text { - в будние, } 20 \% \text { - в выходные и праз- } \\
\text { дничные дни. }\end{array}$ \\
\hline Для туристских фирм & $\begin{array}{l}\text { Специальные тарифы на основные и дополнительные услуги. } \\
\text { Туристским фирмам предоставляется агентское вознагражде- } \\
\text { ние в размере 10\% от стоимости номера и скидка 15\% при } \\
\text { размещении групп от 6 человек. }\end{array}$ \\
\hline Акция «Поймай удачу» & Скидка до 18\% при заселении. \\
\hline Пакет для молодоженов & $\begin{array}{l}\text { Размещение в номере 1 категории с одной двуспальной кро- } \\
\text { ватью, студии или номере люкс на одну ночь; декоративное } \\
\text { оформление номера; фрукты и шампанское в номер; завтрак } \\
\text { в баре или в номере в любое время; возможность позднего } \\
\text { выезда (до 18:00). }\end{array}$ \\
\hline
\end{tabular}

Возможности гостиницы для создания пакета выходного дня ${ }^{3}$

Таблица 3

\begin{tabular}{|l|l|}
\hline \multicolumn{1}{|c|}{ Возможность } & \multicolumn{1}{|c|}{ Применение в пакетировании } \\
\hline Предприятие питания & $\begin{array}{l}\text { В пакеты выходного дня часто включают заказ завтрака в } \\
\text { номер, фруктовое ассорти или другие легкие закуски, обе- } \\
\text { ды и ужины. }\end{array}$ \\
\hline Наличие номеров студий и люкс & Номера данного типа пользуются спросом у пар и семей. \\
\hline Выгодное расположение & $\begin{array}{l}\text { Позволяет организовать досуг гостей: прогулки, посеще- } \\
\text { ние достопримечательностей и учреждений культуры. }\end{array}$ \\
\hline Наличие охраняемой парковки & $\begin{array}{l}\text { Путешествующие по выходным зачастую прибывают на } \\
\text { личном транспорте. }\end{array}$ \\
\hline
\end{tabular}

2 Составлено автором.

3 Составлено автором. 
Помимо внутренних возможностей необходимо проанализировать также внешние факторы: наличие на рынке аналогичных и схожих предложений.

Пакетирование услуг не имеет широкого распространения на гостиничном рынке г. Шахты. Некоторые гостиницы предлагают свадебные пакеты и конференц-пакеты, но их ассортимент очень узок. Анализ сайтов городских гостиниц позволил выявить только один пакет потакания, реализуемый гостиничным комплексом «Триумф»: данный продукт предполагает краткосрочное пребывание гостей в средстве размещения без ночевки. В стоимость входит размещение в номере категории «стандарт» для двоих взрослых и их детей, а также посещение аквазоны.

Пакетов выходного дня не выявлено.

С целью определения круга услуг для включения в пакет был проведен опрос гостей, которые останавливались в гостинице с ноября по декабрь 2017 г.

Гостям было предложено отметить предпочитаемые услуги в списке, обозначив отдельно приоритетные. В результате было получено 20 заполненных анкет, обобщенные данные по ним представлены на рисунке 1.
Таким образом, наибольший интерес вызвали возможность позднего выезда, услуги питания, обслуживание в номере. Из вариантов организации досуга большинство гостей выбрали поход в кинотеатр. Для оказания последней услуги гостинице потребуется выбрать поставщика.

Ближайший кинотеатр расположен в пяти минутах ходьбы, на той же улице, что и гостиница. Стоимость билетов варьируется от 130 руб. за утренний сеанс до 250 руб. за вечерний.

Исходя из данных опроса и выявленных возможностей гостиницы, можно составить следующий пакет:

— размещение на 2 ночи;

- два завтрака;

- обед;

— ужин;

— фруктовое ассорти и бутылка вина в номер;

— билеты на вечерний сеанс в кино;

- возможность позднего выезда.

Для установления цены пакета необходимо установить стоимость отдельных услуг, включенных в него. Но единую цену продукта не следует определять через простое сло-

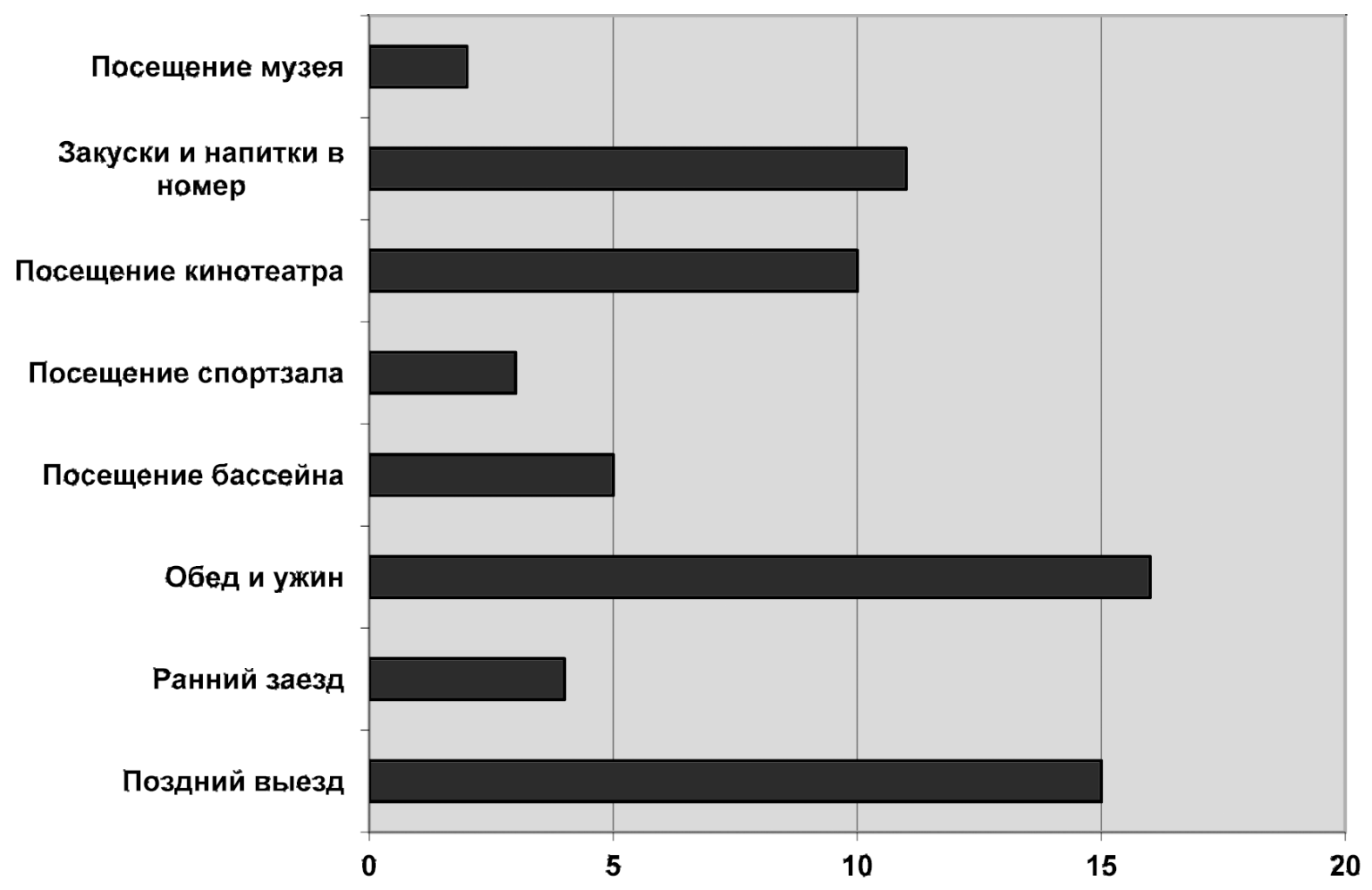

Рис. 1. Предпочитаемые гостями услуги (составлено автором) 
жение услуг в нем. Важной характеристикой пакетной цены является выгода для гостя: услуги вместе должны обойтись ему дешевле, чем по отдельности. Расчет стоимости пакета можно представить в виде таблицы, обозначив в ней размер скидки на каждую составляющую. При определении размера скидки следует руководствоваться следующей рекомендацией: разница между ценой услуги в пакете и базовой не должна превышать 20\% [4].

Продвигать новый продукт можно стандартными для пакетов выходного дня путями: через сайт гостиницы, напрямую путем информирования гостей у стойки администратора, через рассылку по базе постоянных гостей, контекстную рекламу.

\section{Литература}

1. Гостиничный бизнес: организация и технологии: учебное пособие / Т.В. Дегтяре- ва, И. В. Борисенко, Н. Г. Нагай, Н. Т. Обоймова, О.А. Катеринич, О.С. Мысова, О.В. Елисеева; под общ. ред. к.э.н., доцента О.В. Елисеевой. - Шахты: ИСОиП (филиал) ДГТУ в г. Шахты, 2018. - 154 с.

2. Поплавский В.M. Особенности формирования продуктовой стратегии гостиничного предприятия (на примере ООО «Арт-Сити» г. Волгодонск) / В.М. Поплавский, Г.В. Зеленова // материалы VIII Международной студенческой научной конференции «Студенческий научный форум». - 2016. - 83 с.

3. Официальный сайт гостиницы «Кава ди Пьетра» [Электронный ресурс] - Режим доступа: //http://cavadipietra.ru/. (Дата обращения: 11.09.2019 г.).

4. Ценообразование в гостинице (Часть 1)/ Портал ProHotel [Электронный ресурс] — Peжим доступа: //http://prohotel.ru/news-5513/0/. (Дата обращения: 06.10.2019 г.).

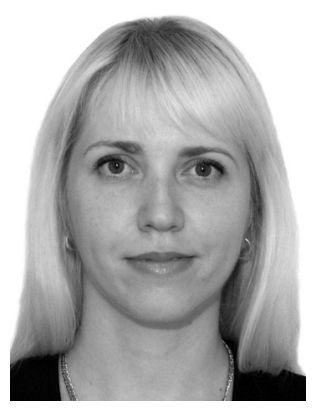

Мысова Ольга Сергеевна - кандидат экономических наук, доцент кафедры «Сервис, туризм и индустрия гостеприимства» Института сферы обслуживания и предпринимательства (филиала) ДГТУ в г. Шахты.

Mysova Olga Sergeevna - $\mathrm{PhD}$ in economics, associate professor of department «Service, tourism and the industry of hospitality» of the Institute of Service Sphere and Entrepreneurship of DSTU (branch) in Shakhty.

345500 , г. Шахты, ул. Пролетарская, 188, уч. корп. 3 188 Proletarskaya st., ed. bld. 3, 345500, Shakhty, Russia Тел.: 8 (928) 151-10-00; e-mail: eliseewa.olga@mail.ru 


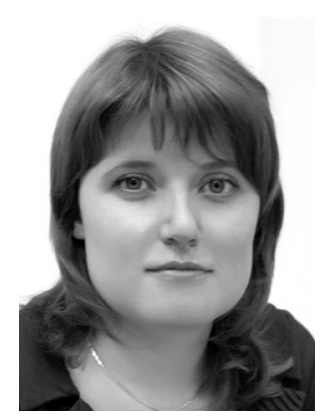

Елисеева Ольга Валерьевна - кандидат экономических наук, доцент кафедры «Сервис, туризм и индустрия гостеприимства» Института сферы обслуживания и предпринимательства (филиала) ДГТУ в г. Шахты.

Eliseeva Olga Valerievna - $\mathrm{PhD}$ in economics, associate professor of department «Service, tourism and the industry of hospitality» of the Institute of Service Sphere and Entrepreneurship of DSTU (branch) in Shakhty.

345500 , г. Шахты, ул. Пролетарская, 188 , уч. корп. 3 188 Proletarskaya st., ed. bld. 3, 345500, Shakhty, Russia

Тел.: 8 (928) 151-10-00; e-mail: eov1974@mail.ru

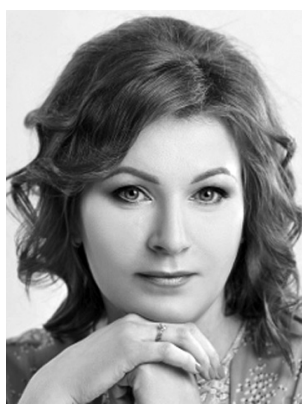

Нагай Наталья Геннадьевна - кандидат экономических наук, доцент кафедры «Сервис, туризм и индустрия гостеприимства» Института сферы обслуживания и предпринимательства (филиала) ДГТУ в г. Шахты.

Nagai Natalia Gennadievna - $\mathrm{PhD}$ in economics, associate professor of department «Service, tourism and the industry of hospitality» of the Institute of Service Sphere and Entrepreneurship of DSTU (branch) in Shakhty.

345500 , г. Шахты, ул. Пролетарская, 188, уч. корп. 3 188 Proletarskaya st., ed. bld. 3, 345500, Shakhty, Russia Тел.: 8 (928) 151-10-00; e-mail: nagay_78@rambler.ru 